\title{
Effect of slow biodegradable substrate addition on biofilm structure and reactor performance in two MBBRs filled with different support media
}

\author{
Ashrafi, Elham; Allahyari, Edris; Torresi, Elena; Andersen, Henrik Rasmus
}

Published in:

Environmental Technology (United Kingdom)

Link to article, DOI:

$10.1080 / 09593330.2019 .1581261$

Publication date:

2020

Document Version

Peer reviewed version

Link back to DTU Orbit

Citation (APA):

Ashrafi, E., Allahyari, E., Torresi, E., \& Andersen, H. R. (2020). Effect of slow biodegradable substrate addition on biofilm structure and reactor performance in two MBBRs filled with different support media. Environmental Technology (United Kingdom), 41(21), 2750-2759. https://doi.org/10.1080/09593330.2019.1581261

\section{General rights}

Copyright and moral rights for the publications made accessible in the public portal are retained by the authors and/or other copyright owners and it is a condition of accessing publications that users recognise and abide by the legal requirements associated with these rights.

- Users may download and print one copy of any publication from the public portal for the purpose of private study or research.

- You may not further distribute the material or use it for any profit-making activity or commercial gain

- You may freely distribute the URL identifying the publication in the public portal 


\title{
Effect of slow biodegradable substrate addition on biofilm structure and reactor performance in two MBBRs filled with different support media
}

\author{
Elham Ashrafi, Edris Allahyari, Elena Torresi \& Henrik Rasmus Andersen
}

To cite this article: Elham Ashrafi, Edris Allahyari, Elena Torresi \& Henrik Rasmus Andersen (2019): Effect of slow biodegradable substrate addition on biofilm structure and reactor performance in two MBBRs filled with different support media, Environmental Technology, DOI: 10.1080/09593330.2019.1581261

To link to this article: https://doi.org/10.1080/09593330.2019.1581261

Accepted author version posted online: 08 Feb 2019.

Submit your article to this journal $\sqsubset$

Џ Article views: 6

View Crossmark data \lceil 
Publisher: Taylor \& Francis \& Informa UK Limited, trading as Taylor \& Francis Group

Journal: Environmental Technology

DOI: $10.1080 / 09593330.2019 .1581261$

Effect of slow biodegradable substrate addition on biofilm structure and reactor performance in two MBBRs filled with different support media

Elham Ashrafia,b*, Edris Allahyaric, Elena Torresid ${ }^{\mathrm{d}}$, Henrik Rasmus Andersend

a Biochemical and Bioenvironmental Research Center (BBRC), Sharif University of Technology, Tehran, Iran

b Water Lab, Sanitary Section, Department of Civil Engineering and Geoscience, Delft University of Technology, Delft, Netherlands.

c Department of Chemical Engineering, Faculty of Engineering, University of Tehran, Tehran, Iran.

d Department of Environmental Engineering, Technical University of Denmark, Bygningstorvet 115, 2800 Kongens Lyngby, Denmark.

*Coresponding author: elham.ashrafi1985@gmail.com

\section{Abstract}

In this study, two moving-bed biofilm reactors $\left(\mathrm{MBBR}_{1}\right.$ and $\left.M B \mathrm{BR}_{2}\right)$ filled with different size of carrier media (Kaldnes $\mathrm{K}_{1}$ and Kaldnes $\mathrm{K}_{1}$ micro, respectively) were subjected to soluble (sugar and sodium acetate (Ac)) substrate and mixture of soluble and particulate (particulate potato starch (PS)) substrate in a very high organic loading rate $\left(12 \mathrm{kgCOD} / \mathrm{m}^{3} \cdot \mathrm{d}\right)$ at different temperatures $\left(26\right.$ and $15^{\circ} \mathrm{C}$, in $\mathrm{MBBR}_{1}$ and $\mathrm{MBBR}_{2}$, respectively). The effects of carrier type and substrate on biofilm structure and reactor performance have been studied. Starch was removed by adsorption at the biofilm surface and hydrolyzed which caused substrate gradient in $\mathrm{MBBR}_{1}$, however, hydrolyzed uniformly within biofilm in $M B B R_{2}$. The biofilm of $\mathrm{MBBR}_{1}$ was irregular due to filamentous structure growth due to the substrate gradient, while, it was regular in $\mathrm{MBBR}_{2}$ due to uniform distribution of substrate. The performance of both MBBRs in ammonium, COD and TN removal decreased significantly when the amount of small particles in the reactor increased owing to feeding by starch, which led to biomass density decline. The type of media affected the quantity and distribution of attached biomass, which in turn influenced the activity of specific microbial functional groups in the biofilm. The biofilm in $\mathrm{MBBR}_{2}$ was thicker and consequently 
nitrogen removal by denitrification was much higher. Lower temperature did not affect negatively the reactor performance in $\mathrm{MBBR}_{2}$.

\section{Key words:}

MBBR, slowly biodegradable substrate, potato starch, simultaneous nitrification de-nitrification (SND), particle size distribution

\section{Introduction}

Compared to the suspended biomass process, Moving Bed Biofilm Reactor (MBBR) has definite advantages such as higher biomass concentration, higher chemical oxygen demand loading, sturdy tolerance to loading impact, longer sludge age, lower hydraulic retention time (HRT), higher volumetric removal rates, no sludge recirculation, relatively small area requirements and no sludge bulking issues $[1,2]$. The MBBR process has proved to be a yery simple and efficient technology in municipal and industrial wastewater treatment strategies. In 2009 there were more than 600 MBBRs operating in 50 countries [3]. The utilization of attached instead of suspended biomass benefits a very compact reactors and easier separation of the bio-solids from the treated effluent [4]. The moving bed biofilm reactor (MBBR) is a growing biofilm technology which has acquire considerable attention in the wastewater treatment in the last 20 years [5]. It is based on the use of generously moving plastic carrier elements with density a little lighter than that of water in which microorganisms form biofilms [6The MBBR technology promotes biofilm attachment and growth on engineered carriers that are maintained in constant suspension. The attached biofilms are preserved and protected from abrasion with other carriers in the interior spaces of the MBBR carriers [7]. Consequently, the biofilm carriers in the MBBR play a significant role in microbial attachment control, as well as the type of reactor operation and process effectiveness. To date, various carriers have been introduced in the MBBR process, including polyethylene plastics, polyurethane sponge, polyvinyl alcohol gel, biodegradable polymer, granular activated carbon, polymer foam pads, nonwoven media, etc., [8-13]. This biofilm process has been extensively used for the treatment of synthetic [14, 15], domestic [16, 17] and industrial wastewaters $[16,18]$.Environmental conditions such as substrate availability and hydrodynamics might lead to various physical structures of biofilms, rough or smooth, porous or compact biofilms [19-22]. Given the benefits presented by the MBBR process such as compactness, flexibility and high quality effluent production, a rapidly growing market for this technology has been established worldwide [4]. Since nitrogen compounds are a significant threat to natural aquatic ecosystems, mainly because they play an important role in the eutrophication process, the environmental legislation has become increasingly 
stringent concerning nitrogen concentration in the effluents from wastewater treatment plants (WWTPs), which are major sources of nitrogen compounds [23]. Traditionally, biological nitrogen removal from wastewater has been accomplished using nitrification and heterotrophic de-nitrification [24]. Since the carrier material employed in MBBR processes effect the attachment and distribution characteristics of the biofilm, it is interesting to understand how the type of support media will influence the activity of nitrifiers in situations where overgrowth of heterotrophs takes place, such information may potentially be used in the selection of appropriate biofilm carriers for MBBRs treating high loaded wastewaters [4]. Most of the studies on MBBR up to now, focused on optimizing its performance, such as the optimal filling degree [25], effect of carrier geometry [26] or microbial community structure [27]. There are lacks of studies, which investigate the biofilm structure development on the carriers in MBBR system, which is fed by particulate substrate (e.g. potato starch) and effect of the carriers' size, temperature and substrate on MBBRs' performance, in COD and nitrogen removal. In the light of this background, this work attempted to evaluate the effect of soluble and particulate substrates on COD and nitrogen conversions in two lab scale MBBRs. In order to perceive the influence of the temperature and support media on MBBR's overall performance as well as on the dynamics of floc and biofilm throughout the experiment, each reactor was filled with different sizes of carriers (same in material and shape) which were operated at different temperatures.

\section{Material and methods}

\subsection{Experimental equipment and carriers}

Two aerobic MBBR systems consisting of an influent tank and reactor were used in this study. The reactors were made of transparent Plexiglas in a rectangular shape (the volume of $\mathrm{MBBR}_{1}$ and $\mathrm{MBBR}_{2}$ were 5.25 and $3 \mathrm{~L}$, respectively) which were aerated by porous stone diffusers located at the bottom of the systems and compressed air was supplied to them. The $\mathrm{pH}$ and DO were constant at 7 and 2 $\mathrm{mg} / \mathrm{L}$, the temperature for $\mathrm{MBBR}_{1}$ and $\mathrm{MBBR}_{2}$ were 26 and $15^{\circ} \mathrm{C}$, respectively. Flow rate for both of MBBRs was $31.5 \mathrm{~L} / \mathrm{d}$. HRT (Hydraulic Retention Time) for $\mathrm{MBBR}_{1}$ and $\mathrm{MBBR}_{2}$ was 4 and $2.3 \mathrm{hr}$, respectively. Kaldnes $\mathrm{K}_{1}$ and Kaldnes $\mathrm{K}_{1}$ micro carriers were used for $\mathrm{MBBR}_{1}$ and $\mathrm{MBBR}_{2}$, which their characteristics are demonstrated in table 1 . In order to have the same surface area for biofilm development in both reactors, the filling fraction was chosen to $40 \%$ and $22 \%$ of the operational volume in the reactors for $\mathrm{MBBR}_{1}$ and $\mathrm{MBBR}_{2}$, respectively.

\subsection{Biomass inoculum}


MBBRs were inoculated with activated sludge taken from Harnaschpolder wastewater treatment plant (South Holland, Netherlands).Total suspended solids (TSS) and volatile suspended solids (VSS) were $3 \mathrm{~g} / \mathrm{L}$ and $2 \mathrm{~g} / \mathrm{L}$ respectively. At first, two MBBRs were started- up with a mixture of sugar and Sodium Acetate (Ac). Once the sugar and Ac were fully converted in the reactors, we added PS in the influent.

\subsection{Influent medium}

The applied synthetic wastewater for both reactors consisted of two media. The media were separated in carbon source (Medium A: C-source with a final concentration of $2 \mathrm{gCOD} / \mathrm{L} ; 3.6 \mathrm{mM} \mathrm{MgSO}_{4} .7 \mathrm{H} 2 \mathrm{O} ; 4.7 \mathrm{mM} \mathrm{KCl}$ ) and medium B $\left(69 \mathrm{mM} \mathrm{NH} 4 \mathrm{Cl} ; 4.2 \mathrm{mM} \mathrm{K}_{2} \mathrm{HPO}_{4} ; 2.1 \mathrm{mM} \mathrm{KH}_{2} \mathrm{PO}_{4} ; 15 \mathrm{~mL}\right.$ milk; $10 \mathrm{~mL} / \mathrm{L}$ trace element solution according to [29]). Every time, $150 \mathrm{~mL}$ of both media was dosed to the reactor together with $1.2 \mathrm{~L}$ of tap water. The final dosage of COD-load and $\mathrm{N}$-load during the experiments were 12 and $21 \mathrm{kgCOD} / \mathrm{m}^{3} \cdot$ day and; 0.6 and 1 $\mathrm{kgN} / \mathrm{m}^{3} \cdot$ day for $\mathrm{MBBR}_{1}$ and $\mathrm{MBBR}_{2}$, respectively. During the first period, a mixture of sugar and sodium acetate (Ac) (ratio 1:1) was used as carbon source for both of reactors, while, in the second period, particulate potato starch (PS) was added as carbon source as well as sugar and sodium acetate (ratio 1:1:1). Starch vessel was continuously stirred [30].

\subsection{Analytical methods}

The analyses are divided in continuous measurements (online), daily to weekly measurements, some other less frequent measurements and the cycle measurements. Total suspended solids (TSS) and volatile suspended solids (VSS) were measured for floc, as described in [31] and for biofilm as described in [4]. Biofilm thickness was determined by microscopy.

$\mathrm{COD}, \mathrm{NH}_{4}{ }^{+}-\mathrm{N}, \mathrm{NO}_{2}-\mathrm{N}, \mathrm{NO}_{3}-\mathrm{N}$ and $\mathrm{TN}$ concentrations in the bulk liquid were determined spectrophotometrically by use of standard test kits (Dr. Lange type LCK; manufacturer: Hach Lange, Dusseldorf, Germany). Particulate COD could be visualized by coloring the starch particles with an Iodine solution prior to microscopy (according to [30]).

\section{Results}

3.1. Biofilm formation

Biomass concentration increased from $1 \mathrm{gVSS} / \mathrm{L}$ at the beginning of the operation to 8 (floc $=3 \mathrm{gVSS} / \mathrm{L}$, biofilm $=5 \mathrm{gVSS} / \mathrm{L}$, fig $1 \mathrm{a}$ ) and $13 \mathrm{gVSS} / \mathrm{L}$ (floc $=4.5 \mathrm{gVSS} / \mathrm{L}$, biofilm $=8.5 \mathrm{gVSS} / \mathrm{L}$, fig $1 \mathrm{a})$ on day 45 for $\mathrm{MBBR}_{1}$ and $\mathrm{MBBR}_{2}$, respectively (30 days for startup). Within 45 days, almost all of the carriers got $80 \%$ and $100 \%$ covered in $\mathrm{MBBR}_{1}$ and $\mathrm{MBBR}_{2}$, respectively (determined by 
microscopy, fig 2). On day 45, with sugar and Ac as substrate, the estimated averaged thicknesses of the biofilm were $0.47 \pm 0.1$ and $1.2 \pm 0.1 \mathrm{~mm}$ in $\mathrm{MBBR}_{1}$ and $\mathrm{MBBR}_{2}$, respectively (fig 2) and the biofilm density were 13 and 32 gVSS/lbiofilm in $\mathrm{MBBR}_{1}$ and $\mathrm{MBBR}_{2}$, respectively (fig 3). These parameters indicated that the biofilm was dense, quite round and smooth in both MBBRs, as observed previously with glucose as substrate [32, 19], that being said, the biofilm in the $\mathrm{MBBR}_{2}$, was even much denser. From day 45 (start of starch addition along with sugar and Ac) to 65, the biomass concentration and density started to decrease due to the biomass washout and biofilm detachment, until 6 gVSS $/ \mathrm{L}$ (floc $=2 \mathrm{gVSS} / \mathrm{L}$, biofilm $=4 \mathrm{gVSS} / \mathrm{L}$, fig $1 \mathrm{~b}$ ) and $6.5 \mathrm{gVSS} / 1 \mathrm{biofilm}$ in $\mathrm{MBBR}_{1}$ and $10 \mathrm{gVSS} / \mathrm{L}$ (floc $=3.5 \mathrm{gVSS} / \mathrm{L}$, biofilm $=6.5 \mathrm{gVSS} / \mathrm{L}$, fig $1 \mathrm{~b}$ ) and 29 gVSS/lbiofilm in $\mathrm{MBBR}_{2}$ (fig 3). Almost $100 \%$ of the carriers were partially covered $\left(50 \%\right.$ covered) in $\mathrm{MBBR}_{1}$, on the other hand, all of carriers in $\mathrm{MBBR}_{2}$ were still $90 \%$ covered (based on the microscopy, fig 4). The biofilm became lighter, softer, less smooth and irregular in both reactors by adding starch (fig 4). Visual observations indicated that the biofilms, which formed during the starch degradation, were mainly detached by sloughing/abrasion (after day 45). The developed biofilm in glucose (sugar) and Ac mixture, was smooth, while, the biofilm obtained in starch was fluffy and rough.SVI 30 increased from 120 to 185 $\mathrm{mL} / \mathrm{gTSS}$ for both MBBRs, after adding PS in the influent. Feeding by PS led to the presence of many small particles in the bulk liquid (fig 5). Presence of those small particles accelerated biomass wash out increase, since, the settling rate of these small particles was lower than the applied settling rate of $12 \mathrm{~m} / \mathrm{h}$ [30]. This phenomenon brought about biomass concentration decline in PS fed period.

\subsection{Reactor performance}

Results of two MBBRs' performance (in 2 periods) are shown in fig 6. Nitrogen removal efficiency during soluble substrate feeding, was $55 \%$ and $75 \%$ in $\mathrm{MBBR}_{1}$ and $\mathrm{MBBR}_{2}$, respectively. In fact according to what Bassin et al. [4] indicated at high organic loading rate; the amount of the utilized nitrogen in order to biomass synthesis became more relevant, consequently, less ammonium was available for nitrification, therefore, the amount of the generated oxidized nitrogen (nitrate/nitrite) decreased and overall nitrogen conservation declined in the bulk. Furthermore, by considering the amount of soluble nitrogen in effluent (as ammonium, nitrite and nitrate) and the expected amount for fully aerated nitrifying reactors with no anoxic zones (calculated by subtracting the utilized nitrogen in biomass growth from the total nitrogen in the influent), it could be realized that $2 \%$ and $25 \%$ of nitrogen in $\mathrm{MBBR}_{1}$ and $\mathrm{MBBR}_{2}$, respectively, were still missing. Possibly, this amount of nitrogen was lost in to the atmosphere in the form of nitrogen gas $\left(\mathrm{N}_{2}\right)$ resulted from de-nitrification, which Bassin et al. 
[4] acquired the same results as well. In $\mathrm{MBBR}_{1}$ with partially covered carriers, which could not get anoxic condition for de-nitrification, it was low (2\%), on the other hand, in $\mathrm{MBBR}_{2}$, with completely full and saturated carriers, the anoxic condition was applied in order to denitrification, thus, $25 \%$ of total nitrogen was disappeared. Total nitrogen removal decreased to $42 \%$ and $58 \%$ in sugar, Ac and $\mathrm{PS}$ fed $\mathrm{MBBR}_{1}$ and $\mathrm{MBBR}_{2}$, respectively, owing to biofilm concentration and thickness deterioration. Nitrification efficiencies were around $70 \%$ and $85 \%$ for sugar and $\mathrm{Ac}$ fed $\mathrm{MBBR}_{1}$ and $\mathrm{MBBR}_{2}$, respectively. Ammonium was not completely removed in both MBBRs fed by sugar and Ac and even decreased to $57 \%$ and $62 \%$ in $\mathrm{MBBR}_{1}$ and $\mathrm{MBBR}_{2}$ fed by sugar, Ac and PS, respectively. Over $96 \%$ and $99 \%$ of filterable COD removal (based on the filterable COD in the effluent) achieved in $\mathrm{MBBR}_{1}$ and $\mathrm{MBBR}_{2}$ fed by mixture of sugar and $\mathrm{Ac}$ as substrate, respectively. Total COD in effluent were $75 \%$ and $85 \%$ in $\mathrm{MBBR}_{1}$ and $\mathrm{MBBR}_{2}$ fed by sugar, Ac and PS, respectively. The sludge growth yields which were evaluated from effluent suspended solids and variations in biomass dry weight in the reactor,were 0.4 and $0.55 \mathrm{gCOD} / \mathrm{gCOD}$ in $\mathrm{MBBR}_{1}$ and $\mathrm{MBBR}_{2}$ fed by sugar and $\mathrm{Ac}$ and 0.39 and $0.3 \mathrm{gCOD} / \mathrm{gCOD}$ in $\mathrm{MBBR}_{1}$ and $\mathrm{MBBR}_{2}$ fed by sugar, Ac and PS, respectively.

\subsection{Starch degradation}

Adsorption of starch onto biofilm could be visualized by submerging a carrier in an iodine solution [30]. The adsorbed starch particles could be seen by brightfield microscopy on the biofilm as black dots after one day feeding (fig $7 \mathrm{a}, \mathrm{b}$ ). After one day aeration, iodine colored particulate starch was not visible on the surface of the bioflm (fig $7 \mathrm{c}, \mathrm{d}$ ), thus, we cut the carriers with a razorblade to see if starch was spread over the surface and inside the biofilm. Black dots were visible inside the biofilm in $\mathrm{MBBR}_{1}$ (fig $7 \mathrm{e}, \mathrm{f}$ ), while, they were not visible inside the biofilm in $\mathrm{MBBR}_{2}$ (fig $7 \mathrm{~g}, \mathrm{~h}$ ). Observations of colored starch demonstrated that one day feeding was sufficient to hydrolyze all the particulate starch on the biofilm surface and inside biofilm in $\mathrm{MBBR}_{2}$, though, it was sufficient to hydrolyze starch only on the surface of the biofilm (not inside biofilm) in MBBR . Whereas De Kreuk et al. [30] indicated that, one hour anaerobic feeding was insufficient to hydrolyze all particulate starch on the granule surface. Even after more than two hours aeration, iodine colored particulate starch was still visible on the surface of the granules Furthermore, soluble substrate (e.g. sugar or Ac), adsorbed mostly onto the surface of the biofilm which caused a slow release and consumption of hydrolyzed substrate near the surface, while PS might be able to penetrate more into the biofilm, thus, it might be hydrolyzed and consumed more at the inside of the biofilm. 


\section{Discussion}

4.1. Effect of carrier type on attached biomass accumulation and biofilm sloughing

According to the literatures, the key factor in MBBR design is the available effective surface area for biomass growth [33, 34]. In this regard, when the specific surface area is definedfor a given carrier, its size and shape are not usually notable in design purposes [33]. In this study, the media filling ratio was chosen in order to get the same specific area for biofilm growth in both reactors. Due to this fact, since both MBBRs were subjected to the same feeding pattern, similar attached biomass concentrations were expected in both systems, while, it was observed that the Kaldnes $\mathrm{K}_{1}$ micro carriers (media used in $\mathrm{MBBR}_{2}$ ) allowed obtaining higher attached biomass concentrations compared to those reached in $\mathrm{MBBR}_{1}$, where the Kaldnes $\mathrm{K}_{1}$ were employed as support media. These findings suggested that the amount of the attached biomass, which could be achieved in a MBBR system, did not only depend on the theoretical biofilm surface area shown by the support material, but also on the carrier configuration and size. The Kaldnes $\mathrm{K}_{1}$ micro carriers in $\mathrm{MBBR}_{2}$ were much smaller than the conventional Kaldnes $\mathrm{K}_{1}$ and the grown biofilm inside them were more packed and dense. This condition favored the attachment of biofilm and the amount of the detached solids tended to decrease.

4.2. Influence of starch and carrier type on biofilm morphology

As De Kreuk et al. [30] described in their study, in systems without substrate gradients (suspended biomass in flocs), regular and compact structures are anticipated, whereas in systems with substrate gradients, filamentous organisms will proliferate. Martins et al. $[35,36]$ have indicated that in activated sludge systems, suspended solids are incorporated in the open sludge flocs, where the hydrolysis within the floc triggers a constant release of substrate. More or less the same (low) substrate concentration is available throughout the entire floc, consequently micro-gradient would be missing, extreme outgrowth of filamentous organisms would be diminished and sludge bulking would be prohibited. Contrary, in aerobic granules [30] and $\mathrm{MBBR}_{1}$ system in this study (fig $7 \mathrm{e}, \mathrm{f}$ ), starch was mainly hydrolyzed at the surface of the granules and biofilm. Produced substrate was consumed locally, boosted substrate gradients inside the granules or biofilm and incited the outgrowth of filamentous structures. This was in line with other biofilm and fully aerated aerobic granular sludge researches, which low substrate concentrations in the reactor jointly with the presence of oxygen (or nitrate) led to irregular growth of aggregates [30, 3739]. On the other hand, in biofilm system in $\mathrm{MBBR}_{2}$, PS was adsorbed at the 
biofilm surface and mostly hydrolyzed inside the biofilm (fig $7 \mathrm{~g}$, h) which commenced the persistent release of substrate, thus, there was no substrate gradient inside biofilm in $\mathrm{MBBR}_{2}$ and regular biofilm without any filamentous structure were grown inside $\mathrm{MBBR}_{2}$. It can be included thatKaldnes $\mathrm{K}_{1}$ micro carriers preserved regular biofilm without any filamentous structure and resistant against slowly biodegradable substrate. Kaldnes $\mathrm{K}_{1}$ carriers, which were inside $\mathrm{MBBR}_{1}$ have had less dense biofilm which were washed out in large amount by adding PS (fig 8).

\subsection{Influence of substrate and carrier type on nitrogen removal}

Starch removal mechanism deteriorated total nitrogen removal, which remained lower than those reported in studies using acetate as substrate. Nitrogen removal was $55 \%$ and $42 \%$ in $\mathrm{MBBR}_{1}$ fed by sugar, Ac and fed by sugar, Ac, PS, respectively, and $75 \%$ and $58 \%$ for the $\mathrm{MBBR}_{2}$ fed by sugar, Ac and fed by sugar, Ac and PS respectively. This decline could be explained by biomass wash out due to slow hydrolyze of PS. Same results were perceived for nitrification and ammonium removal. Ammonium removal was $70 \%$ and $57 \%$ in $\mathrm{MBBR}_{1}$ fed by sugar, Ac and fed by sugar, Ac, PS, respectively, and $85 \%$ and $62 \%$ in $\mathrm{MBBR}_{2}$ fed by sugar, Ac and sugar, Ac and PS, respectively. Deficiency of simultaneous nitrification and de-nitrification (SND) could be elucidated by partially covered (not saturated by biofilm) Kaldnes $\mathrm{K}_{1}$ carriers which caused low nitrogen removal in $\mathrm{MBBR}_{1}$. A quota of nitrogen in the influent, which was not back as oxidized nitrogen (nitrite and nitrate) or residual non nitrified ammonium, was feasibly removed via de-nitrification as Bassin et al. [4] mentioned in their work as well. Despite the fact that aerobic condition was predominated in the bulk liquid, the thick biomass layer on the carrier media in $\mathrm{MBBR}_{2}$ (Kaldnes $\mathrm{K}_{1}$ micro) resulted in oxygen mass transfer limitation and enabled anoxic condition establishment in the inner zone of the biofilm, where de-nitrification could take place. Therefore nitrogen removal in $\mathrm{MBBR}_{2}$ was superior compared to $\mathrm{MBBR}_{1}$.

Taking into account that the amount of utilized nitrogen for biomass growth was similar in both systems, the observed higher nitrogen loss in $\mathrm{MBBR}_{2}$ was possibly due to the higher thickness of the biofilm in protected surface area of the carrier, which favored development of anoxic environment in $\mathrm{MBBR}_{2}$. Derived results from this study suggested that simultaneous nitrification and denitrification (SND) could be accomplished in MBBR reactors which are preserved under high bulk oxygen concentration with no deliberate anoxic phase, provided that the biofilm is sufficiently thick $(1.2 \mathrm{~mm} \pm 0.1 \mathrm{~mm})$. Furthermore, the magnitude of SND and the associated nitrogen removal were dependent on the specific carrier type. These observations emphasized the requirement for considering not only the effective surface area, but also the configuration of the 
media (e.g., size and shape) and the biofilm characteristics (thickness and biomass content) for better description of the biological conversions.

\subsection{Influence of temperature on two reactors' performance}

The relationship between nitrifying kinetics and temperature has been adequately modeled in previous studies between temperatures of 10 to $28^{\circ} \mathrm{C}$ using the Arrhenius temperature correction coefficient $(\theta)$; with $\theta$ values being reported between $1.086-1.109$ and an average $\theta$ value of 1.09 being suggested for MBBR systems [40]. The relation between nitrification rate and temperature can be found as equation 1 [41]:

$K_{2}=K_{1} \theta\left(T_{2}-T_{1}\right)$

where $\theta$ is the Arrhenius correction coefficient, $K$ is the removal rate $\left(\mathrm{gN} / \mathrm{m}^{2} \cdot \mathrm{d}\right.$ ) and $\mathrm{T}$ is temperature $\left({ }^{\circ} \mathrm{C}\right)$. As the influent nitrogen surface loading rate were 1.2 and $1.1 \mathrm{gN} / \mathrm{m}^{2} \cdot \mathrm{d}$ in $\mathrm{MBBR}_{1}$ and $\mathrm{MBBR}_{2}$, respectively and the effluent ammonium surface rate were 0.24 and $0.23 \mathrm{gN} / \mathrm{m}^{2} \cdot \mathrm{d}$ (fig $6 \mathrm{a}$, b; the effluent concentration of ammonium were $20 \mathrm{mg} / \mathrm{L}$ in both reactors), it can be inferred that the nitrogen removal rate were 0.96 and $0.88 \mathrm{gN} / \mathrm{m}^{2} \cdot \mathrm{d}$ in $\mathrm{MBBR}_{1}$ and $\mathrm{MBBR}_{2}$, respectively. The nitrogen removal rate in MBBR $2\left(\mathrm{~K}_{\mathrm{MBBR} 2}\right)$, calculated according to equation (1), was $0.37 \mathrm{gN} / \mathrm{m}^{2} \cdot \mathrm{d}$. $\left(0.96=K_{M B B R 2}(1.09)(26-15) \rightarrow \mathrm{K}_{\mathrm{MBBR} 2}=0.37 \mathrm{gN} / \mathrm{m}^{2} . \mathrm{d}\right)$

The achieved removal rate in $\mathrm{MBBR}_{2}$ from experiments (fig 6b), indicated that the removal rate was 2.38 times higher than what equation (1) says, thus, the temperature effect on nitrogen removal in $\mathrm{MBBR}_{2}$ was not considerable.

\section{Conclusions}

Particulate substrate (e.g. Starch) in the influent of $\mathrm{MBBR}_{1}$ (filled by Kaldnes $\mathrm{K}_{1}$ media) was removed by adsorption at the biofilm surface, after which it was hydrolyzed. The substrate gradients that came into existence due to the hydrolysis caused irregular filamentous outgrowth on the biofilm. While, starch in the $\mathrm{MBBR}_{2}$ (filled by Kaldnes $\mathrm{K}_{1}$ micro) was hydrolyzed inside the biofilm and uniformly within biofilm which there was no substrate gradient and no filamentous structure; the biofilm in $\mathrm{MBBR}_{2}$ was regular and much denser. The size of carrier directly influenced the distribution and amount of attached biomass. Total nitrogen removal was achieved as a result of nitrogen assimilation by heterotrophs and denitrifying activity in the inner (anoxic) layer of the biofilm, despite the maintenance of high bulk oxygen concentrations in both reactors (especially in $\mathrm{MBBR}_{2}$ which there was thicker biofilm, total nitrogen removal efficiency was pretty higher), which even lower temperature of $\mathrm{MBBR}_{2}\left(15^{\circ} \mathrm{C}\right)$ could not affect the reactor performance negatively in COD and nitrogen removal. 


\section{References}

[1] McQuarrie JP, Boltz JP. Moving bed biofilm reactor technology: process applications, design, and performance. Water Environ Res. 2011; 83(6):560-575.

[2] Leyva-Díaz JC, Calderón K, Rodríguez FA, et al. Comparative kinetic study between moving bed biofilm reactor-membrane bioreactor and membrane bioreactor systems and their influence on organic matter and nutrients removal. Biochem Eng J. 2013; 77:28-40.

[3] Chen X, Kong L, Wang X, et al. Accelerated start-up of moving bed biofilm reactor by using a novel suspended carrier with porous surface. Bioprocess Biosyst Eng. 2015; 38:273-285.

[4] Bassin JP, Dias IN, Cao SMS, et al. Effect of increasing organic loading rates on the performance of moving-bed bio-film reactors filled with different support media: Assessing the activity of suspended and attached biomass fractions. Process Saf and Environ Prot. 2016 Mar; 100:131-141.

[5] Barwal A, Chaudhary R. To study the performance of bio-carriers in moving bed biofilm reactor (MBBR) technology and kinetics of biofilm for retrofitting the existing aerobic treatment systems: a review. Rev in Environ Sci and Bio/Technol. 2014 Sep; 13(3):285-299.

[6] Ødegaard H. Innovation in wastewater treatment: the moving bed biofilm process. Water Sci Technol. 2006; 53:17-33.

[7] Young B, Delatolla R, Kennedy K, et al. Low temperature MBBR nitrification: Microbiome analysis. Water Res. 2017 Mar 15; 111:224-233.

[8] Rouse JD, Burica O, Strazar M, et al. A pilot-plant study of a moving bed biofilm reactor system using PVA gel as a bio-carrier for removals of organic carbon and nitrogen. Water Sci Technol. 2007; 55:135-141.

[9] Bertin L, Lampis S, Todaro D, et al. Anaerobic acidogenic digestion of olive mill wastewaters in biofilm reactors packed with ceramic filters or granular activated carbon. Water Res. 2010; 44:4537-4549.

[10] Guo W, Ngo HH, Dharmawan F, et al. Palmer roles of polyurethane foam in aerobic moving and fixed bed bioreactors. Bioresour Technol. 2010; 101:1435-1439.

[11] Nguyen/TT, Ngo HH, Guo WS, et al. Effects of sponge size and type on the performance of an up-flow sponge bioreactor in primary treated sewage effluent treatment. Bioresour Technol. 2010; 101:1416-1420.

[12] Chu L, Wang J. Nitrogen removal using biodegradable polymers as carbon source and biofilm carriers in a moving bed biofilm reactor. Chem Eng J. 2011 May 15; 170(1):220-225.

[13] Wu W, Yang F, Yang L. Biological denitrification with a novel biodegradable polymer as carbon source and biofilm carrier. Bioresour Technol. 2012; 118:136-140. 
[14] Bassin JP, Kleerebezem R, Dezotti M, et al. Simultaneous nitrogen and phosphate removal in aerobic granular sludge reactors operated at different temperatures. Water Res. 2012; 46:3805-3816.

[15] Hoang V, Delatolla R, Abujamel T, et al. Nitrifying moving bed biofilm reactor (MBBR) biofilm and biofilm response to long term exposure to $1{ }^{\circ} \mathrm{C}$. Water Res. 2014;49:215-224.

[16] Bassin JP, Dezotti M, Sant'Anna JrGL. Nitrification of industrial and domestic saline wastewaters in moving bed biofilm reactor and sequencing batch reactor. J Hazard Mater. 2011 Jan $15 ; 185(1): 242-248$.

[17] Calderón K, Martín-Pascual J, Poyatos JM, et al. Comparative analysis of the bacterial diversity in a lab-scale moving bed biofilm reactor (MBBR) applied to treat urban wastewater under different operational conditions. Bioresour Technol. 2012; 121:119-126.

[18] Dvořák L, Lederer T, Jirků V, et al. Removal of aniline, cyanides and diphenylguanidine from industrial wastewater using a full-scale moving bed biofilm reactor. Process Biochem. 2014 Jan; 49(1):102-109.

[19] Stoodley P, Boyle JD, DeBeer D, et al. Evolving perspectives of biofilm structure. Biofouling. 1999; 14(1):75-90.

[20] Mosquera-Corral A, Montras J, Heijnena J, et al. Degradation of polymers in a biofilm airlift suspension reactor. Water Res. 2003; 37:485-492.

[21] Wagner M, Taherzadeh D, Haisch C, et al. Investigation of the meso scale structure and volumetric features of biofilms using optical coherence tomography. Biotechnol Bioeng. 2010; 107(5):844-853.

[22] Li Ch, Felz S, Wagner M, et al, Investigating biofilm structure developing on carriers from lab-scale moving bed biofilm reactors based on light microscopy and optical coherence tomography, Bioresour Technol.2016;200:128-136.

[23] Pal L, Kraigher B, Brajer-Humar B, et al. Total bacterial and ammonia-oxidizer community structure in moving bed biofilm reactors treating municipal wastewater and inorganic synthetic wastewater. Bioresour Technol. 2012; 110:135-143.

[24] Reboleiro-Rivas P, Martín-Pascual J, Juárez-Jiménez B, et al. Nitrogen removal in a moving bed membrane bioreactor for municipal sewage treatment: Community differentiation in attached biofilm and suspended biomass. Chem Eng J. 2015; 277:209-218.

[25] Gu Q, Sun T, Wu G, et al. Influence of carrier filling ratio on the performance of moving bed biofilm reactor in treating coking wastewater. Bioresour Technol. 2014 Aug; 166:72-78.

[26] Levstek M, Plazl I. Influence of carrier type on nitrification in the moving bed biofilm process. Water Sci Technol. 2009; 59(5):875-882. 
[27] Zhang S, Wang Y, He W, et al. Linking nitrifying biofilm characteristics and nitrification performance in moving-bed biofilm reactors for polluted raw water pretreatment. Bioresour Technol. 2013 Oct; 146:416-425.

[28] PracticalFishkeeping.co.uk [internet]. Peterborough: Practical Fishkeeping; [2016 Jun 13]. Available from: http://www.practicalfishkeeping.co.uk

[29] Vishniac W, Santer M. The Thiobacilli. Bacteriol Rev. 1957 Sep; 21(3):195-213.

[30] De Kreuk MD, Kishida N, Tsuneda S, et al. Behavior of polymeric substrates in an aerobic granular sludge system. Water Res. 2010; 44:5929-5938.

[31] De Kreuk MK, Heijnen JJ, van Loosdrecht MCM. Simultaneous COD, nitrogen and phosphate removal by aerobic granular sludge. Biotechnol Bioeng. 2005; 90(6):761-769.

[32] Villaseńor JC, Van Loosdrecht MCM, Picioreanu C, et al. Influence of different substrates on the formation of biofilms in a biofilm airlift suspension reactor. Water Sci Technol. 1998 Jan; 41(4):323-330.

[33] Ødegaard H, Gisvold B, Strickland J. The influence of carrier size and shape in the moving bed biofilm process. Water Sci Technol. 2000; 41:383-391.

[34] Ferrai M, Guglielmi G, Andreottola G. Modelling respirometric tests for the assessment of kinetic and stoichiometric parameters on MBBR biofilm for municipal wastewater treatment. Environ Model and Softw. 2010 May; 25(5):626-632.

[35] Martins AMP, Picioreanu C, Heijnen JJ, et al. Three-dimensional dual-morphotype species modeling of activated sludge flocs. Environ Sci Technol. 2004; 38(21):5632-5641.

[36] Martins AMP, Karahan O, Van Loosdrecht MCM. Effect of polymeric substrate on sludge settle-ability. Water Res. 2011; 45:263-273.

[37] McSwain BS, Irvine RL, Wilderer PA. The effect of intermittent feeding on aerobic granule structure. Water Sci Technol. 2004; 49(11-12):19-25.

[38] Mosquera-Corral A. de Kreuk MK, Heijnen JJ, et al. Effects of oxygen concentration on Nremoval in an aerobic granular sludge reactor. Water Res. 2005; 39(12):2676-2686.

[39] Picioreanu C, Van Loosdrecht MCM, Heijnen JJ. Effect of diffusive and convective substrate transport on biofilm structure formation: a two-dimensional modeling study. Biotechnol Bioeng. 2000 Sep 5; 69(5):504-515.

[40] Salvetti R, Azzellino A, Canziani R, Bonomo L. Effects of temperature on tertiary nitrification in moving-bed biofilm reactors. Water Res. 2006; 40: 2981- 2993.

[41] Young B, Delatolla R, Kennedy K, Laflamme E, Stintzi A. Low temperature MBBR nitrification: Microbiome analysis. Water Res. 2017; 111: 224-233. 

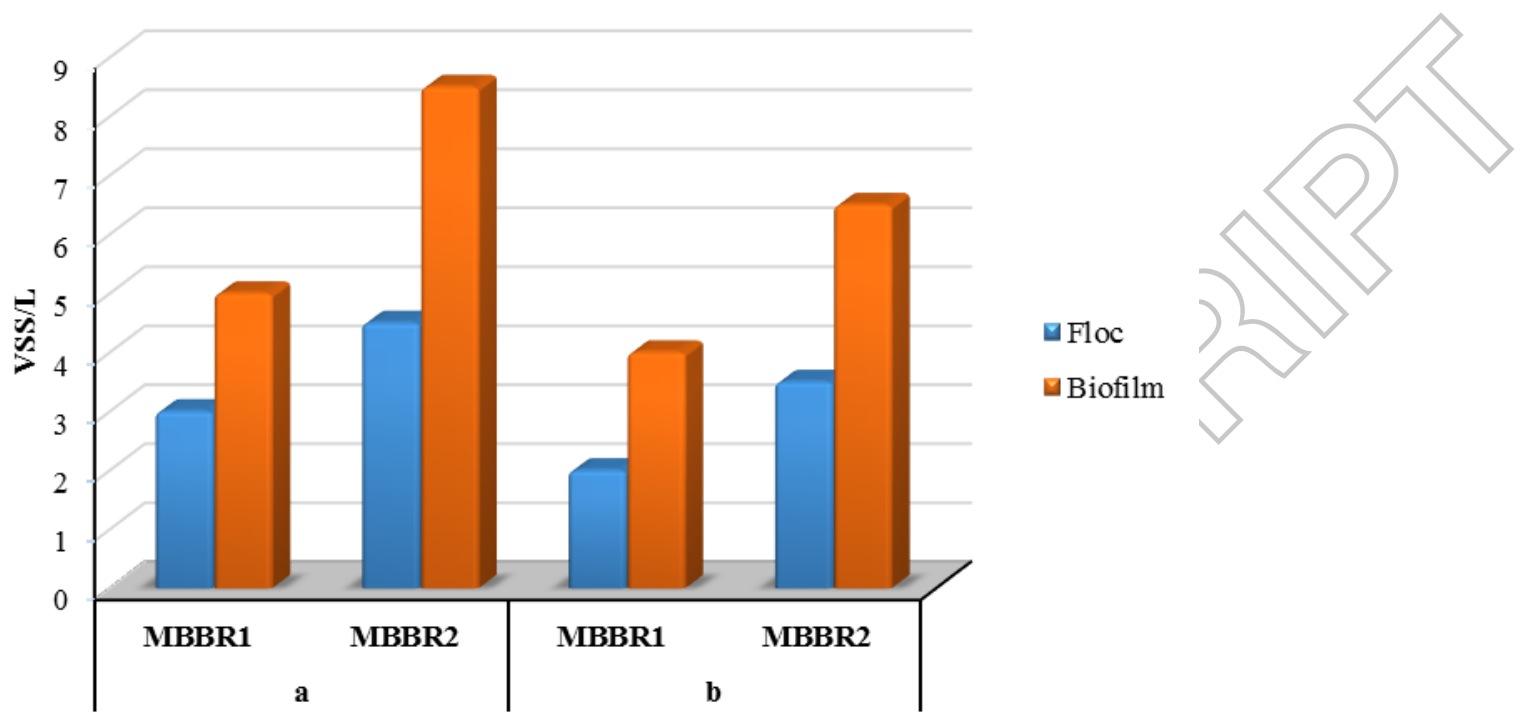

Fig 1: Biomass (floc and biofilm) concentration in $\mathrm{MBBR}_{1}$ and $M B \mathrm{MR}_{2}$ in soluble substrate fed period (a) and soluble with particulate substrate fed period (b) 

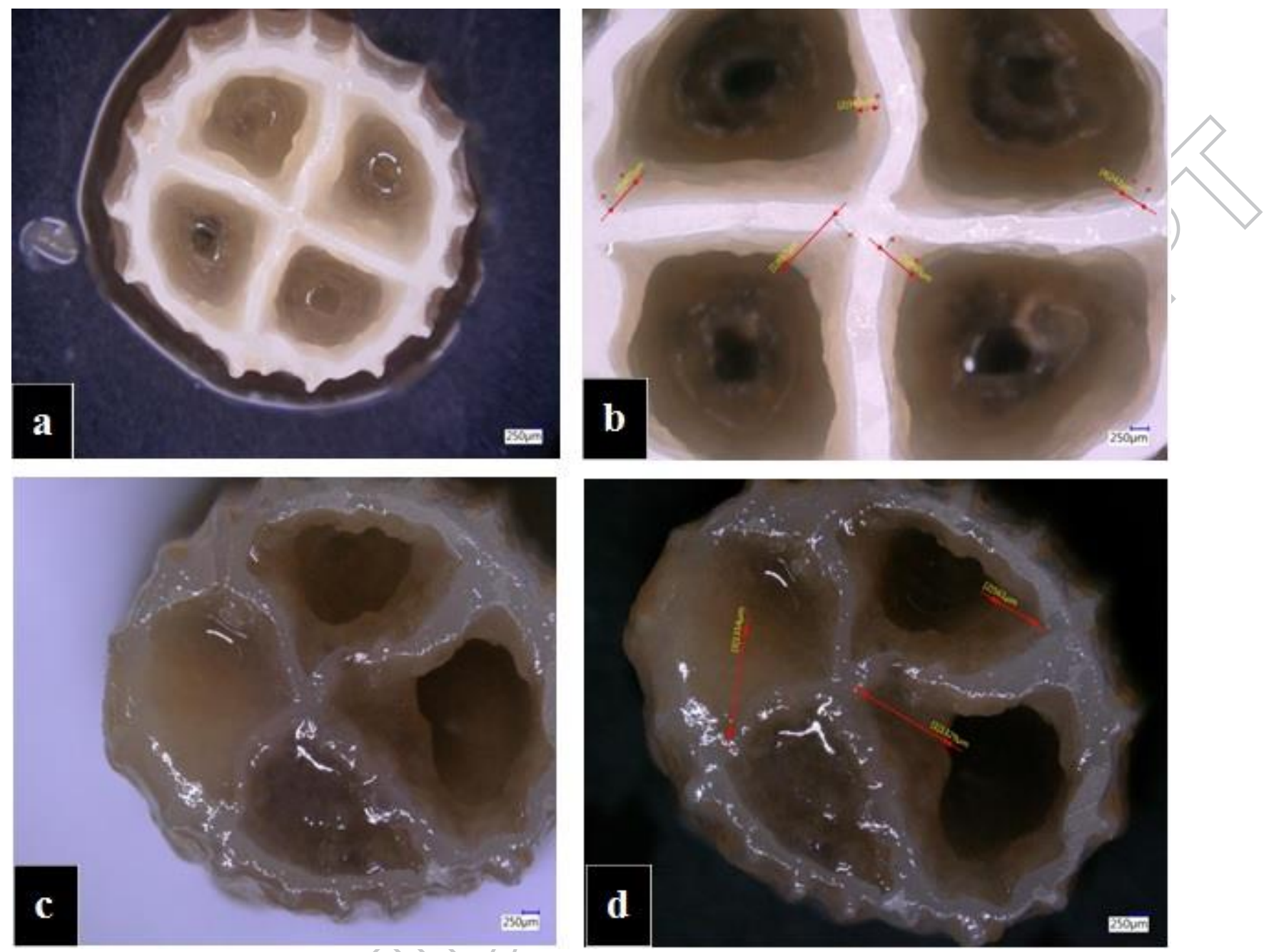

Fig 2: Covered carriers and biofilm thickness in Sugar and sodium acetate feed MBBR (MBBR

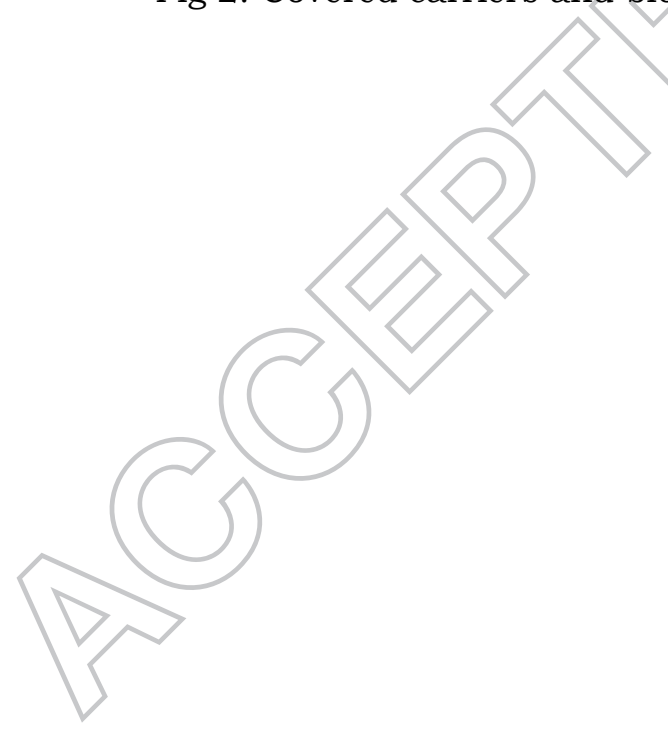
$\mathrm{a}, \mathrm{b}$ and $\left.\mathrm{MBBR}_{2} \mathrm{c}, \mathrm{d}\right)$ 


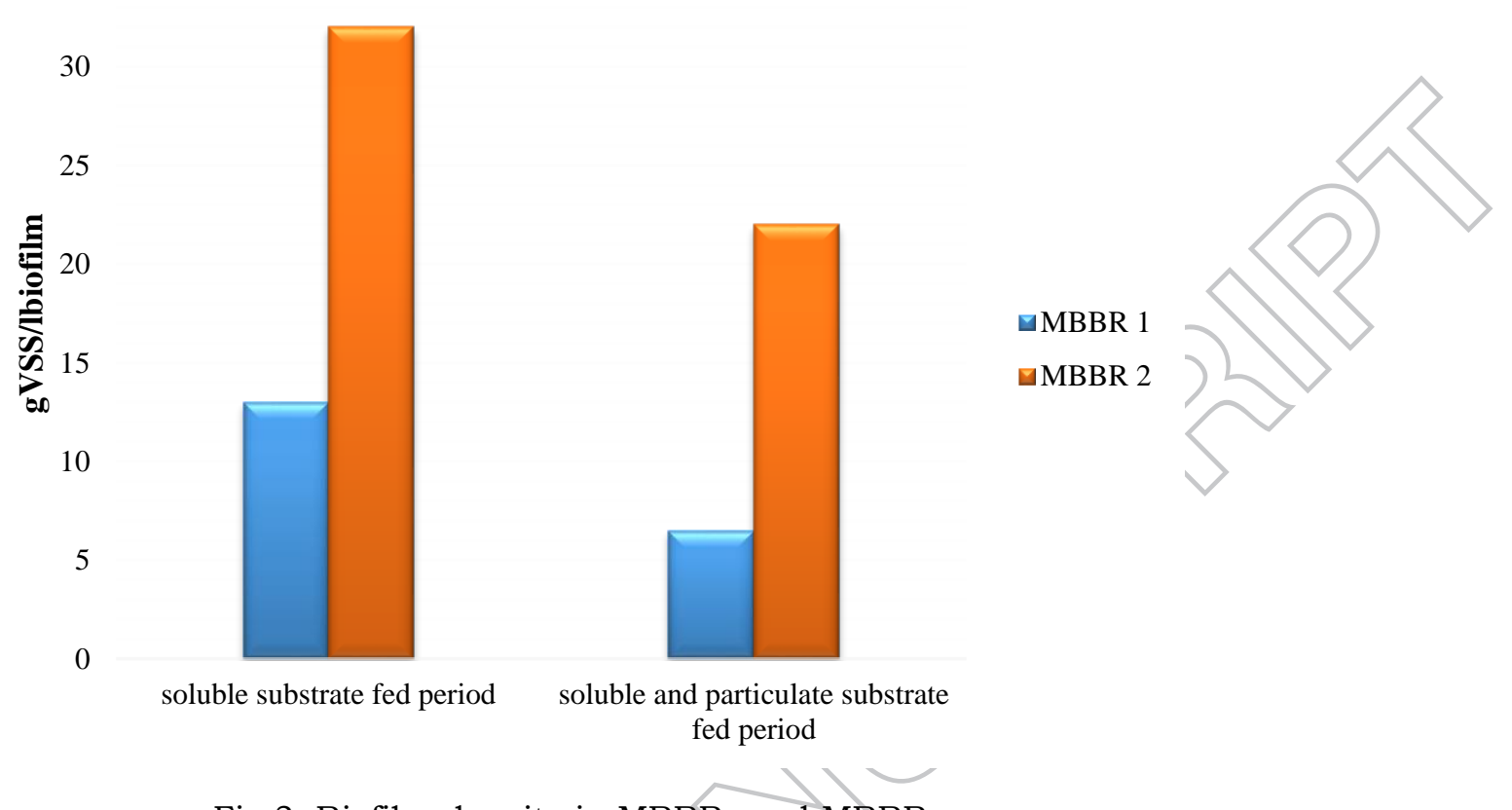

Fig 3: Biofilm density in $\mathrm{MBBR}_{1}$ and $\mathrm{MBBR}_{2}$

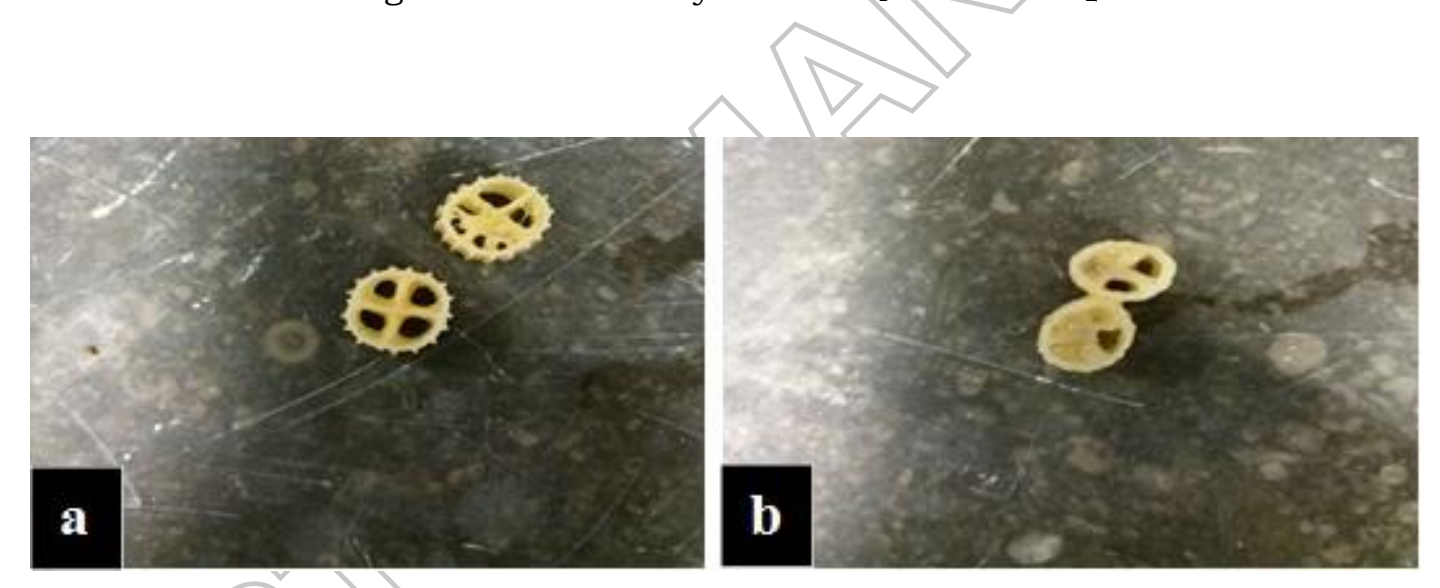

Fig 4: Less dense and irregular biofilm after adding PS, in $\mathrm{MBBR}_{1}$, carriers are $50 \%$ covered (a) and in $\mathrm{MBBR}_{2}$, carriers are still $90 \%$ full (b) 

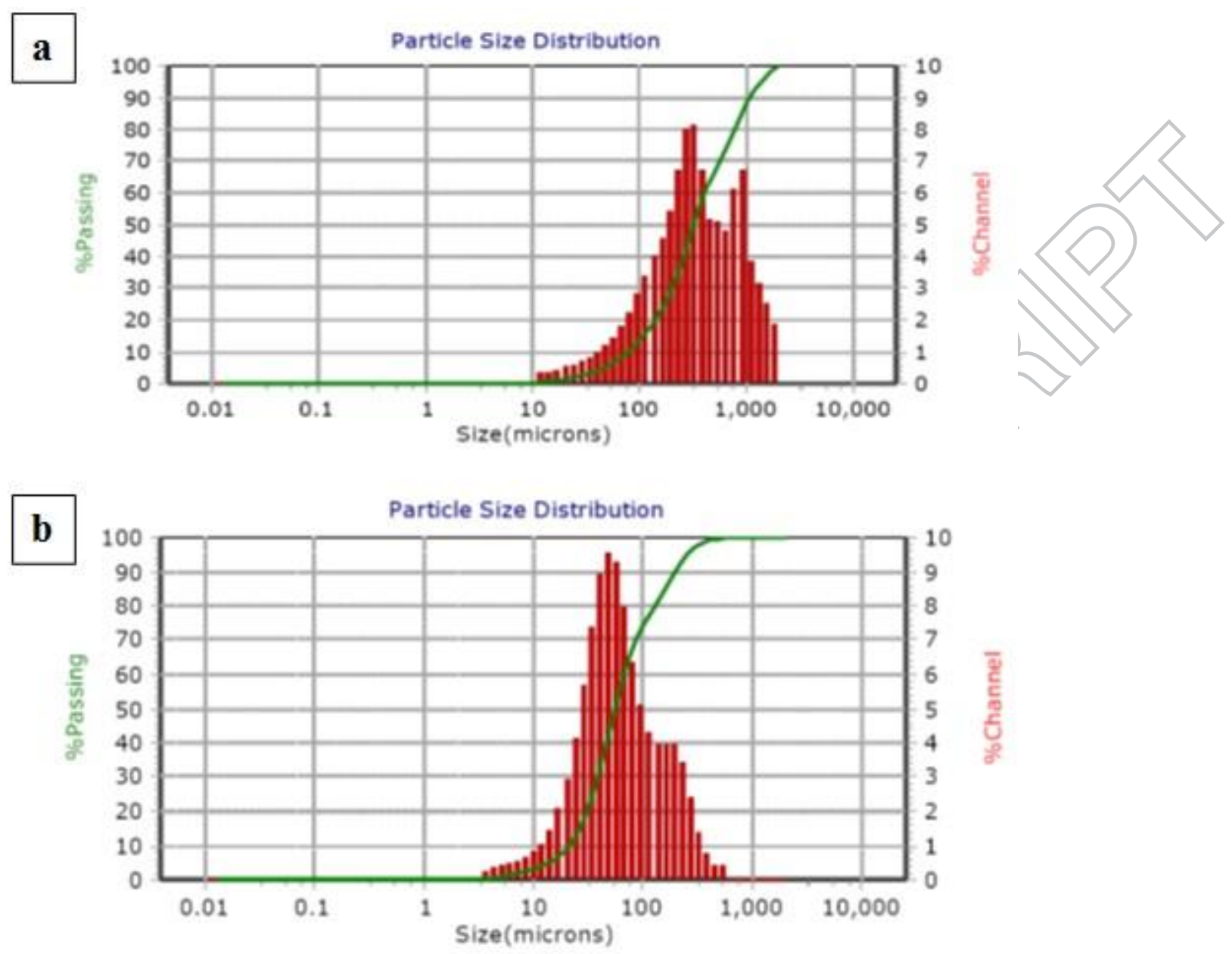

Fig 5: Particle size distribution of sugar and Ac fed (a) and PS fed (b) both MBBRs; in soluble fed system (a), particles are mostly between 100-1000 micron but in PS fed system, particles are mostly between $20-80$ micron (b) 
MBBR1 fed by sugar and Ac

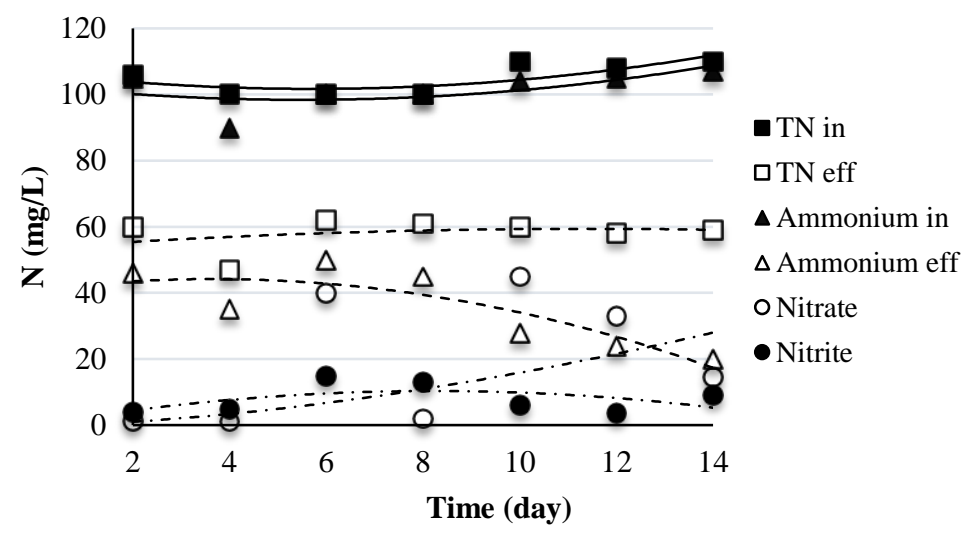

MBBR1 fed by sugar, Ac and PS

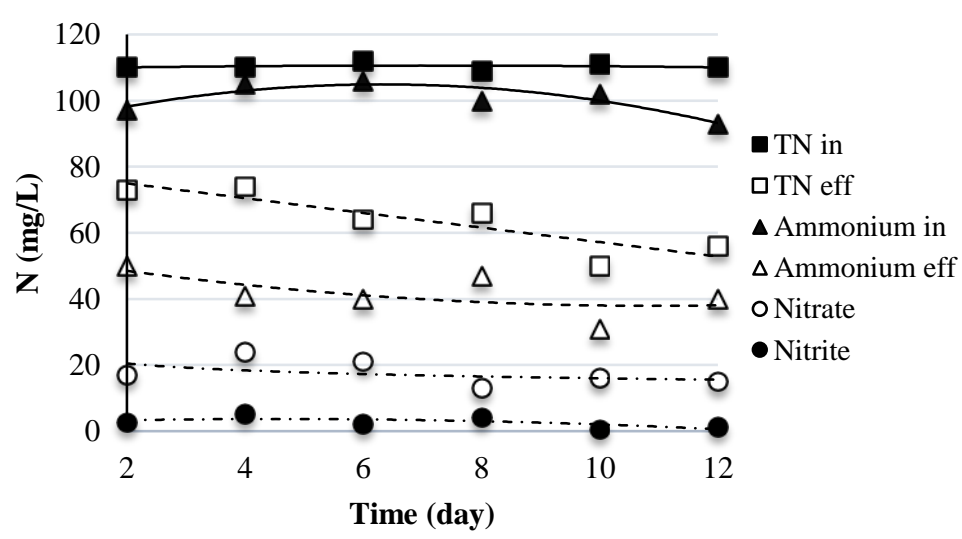

MBBR2 fed by sugar and Ac
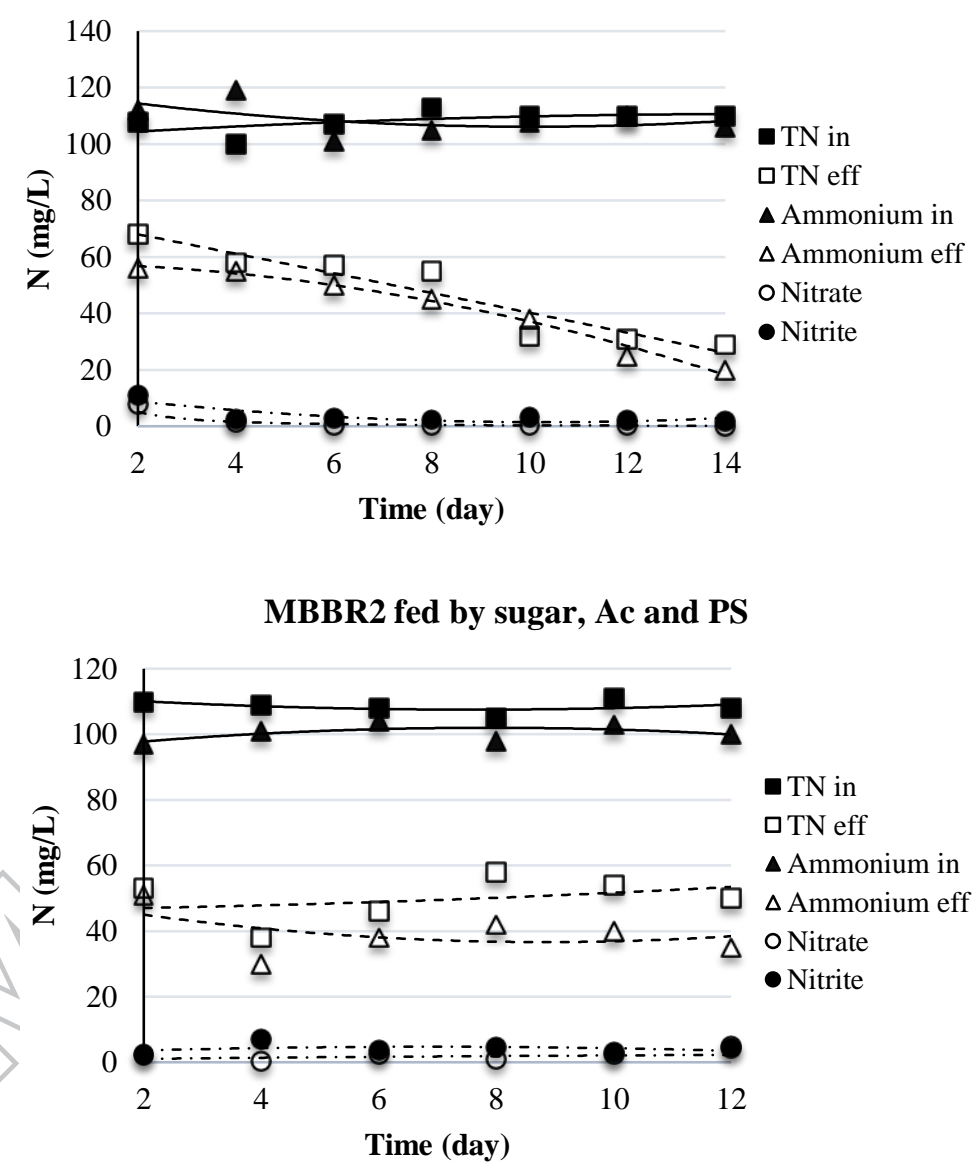

Fig 6: Nitrogen concentrations in influent and effluent of MBBRs at 2 different patterns of feeding 

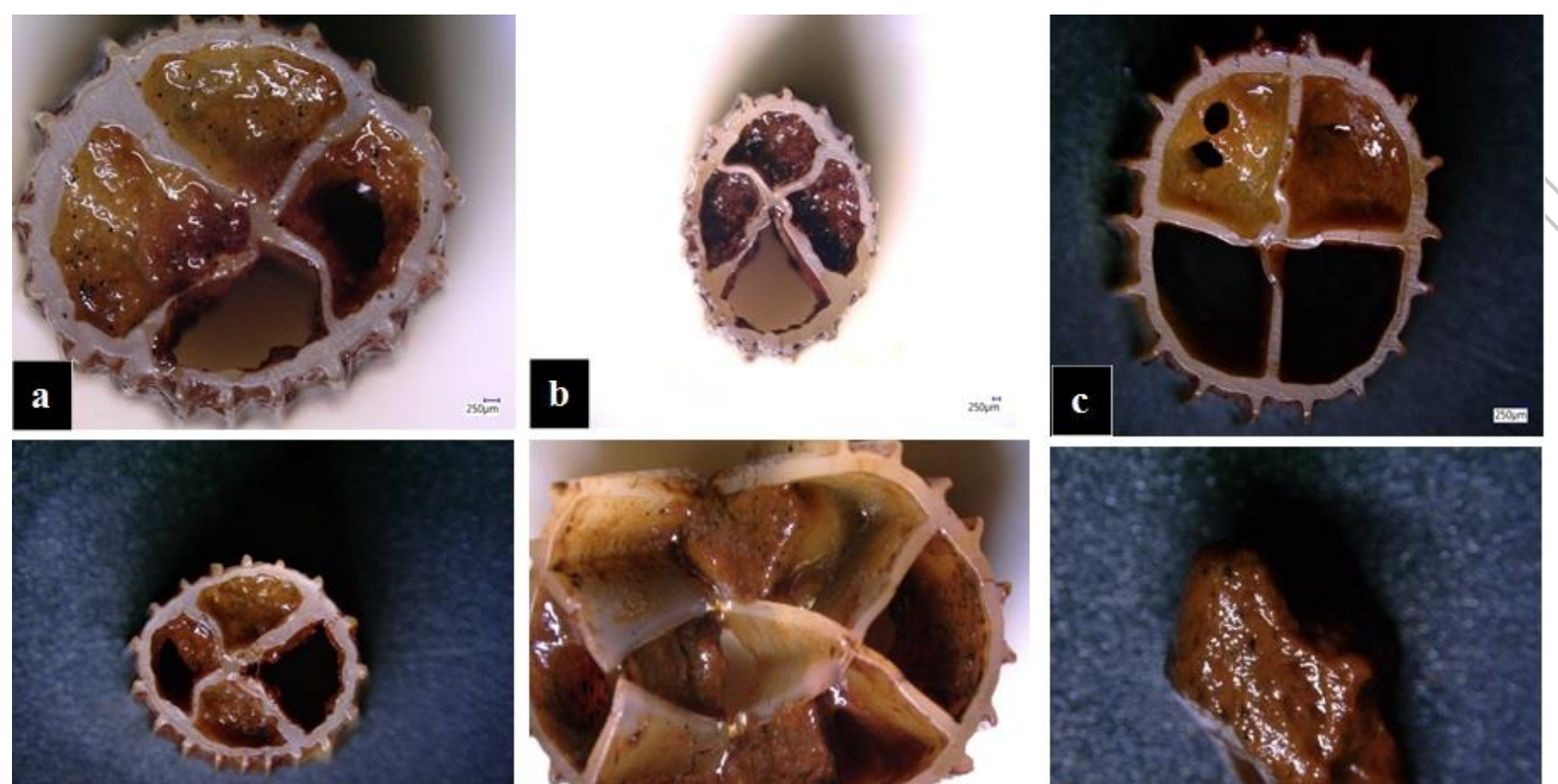

d
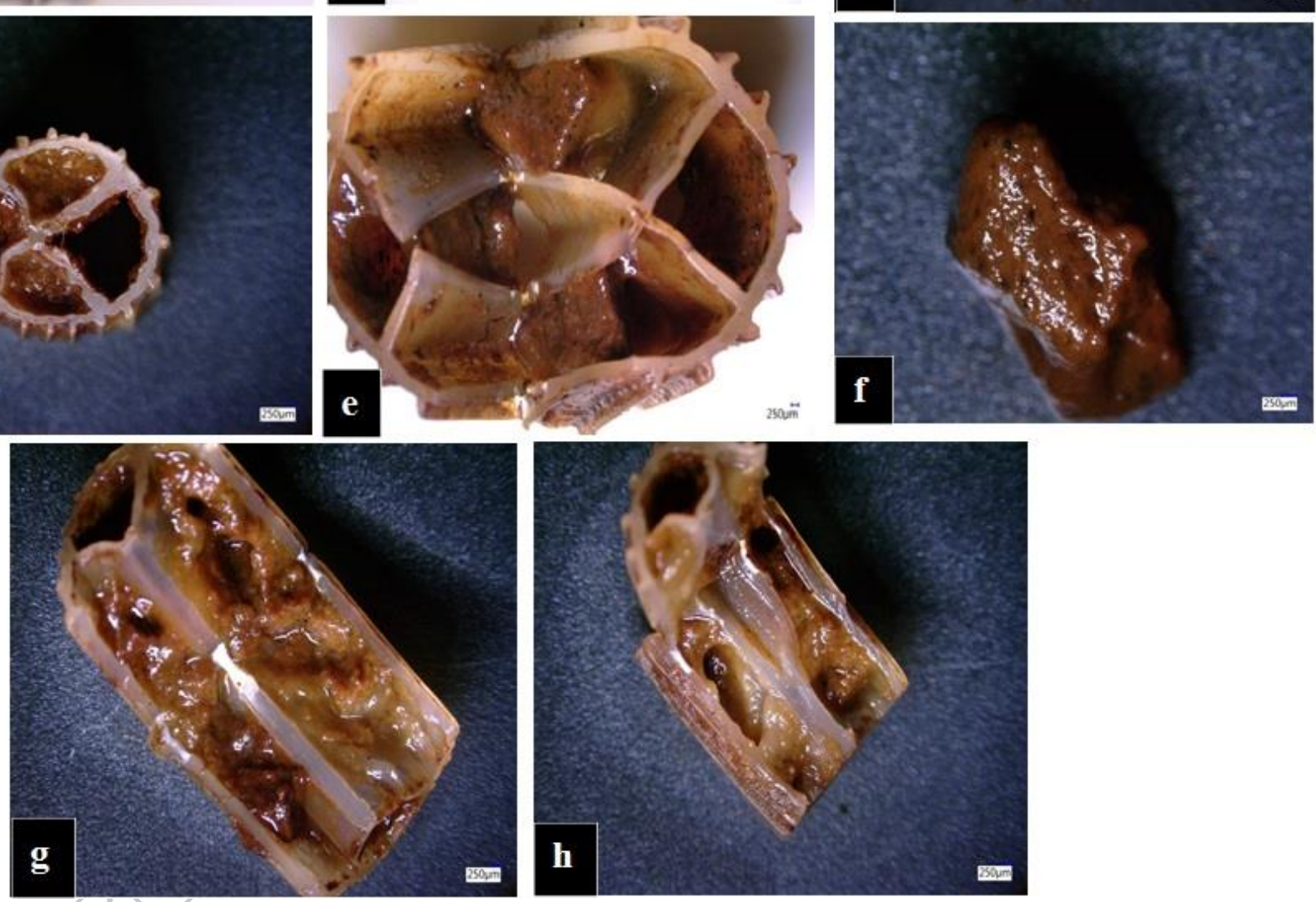

Fig 7: Starch adsorption and slow degradation, illustrated by iodine colored biofilm (starch is colored purple) after the feeding period in $\operatorname{MBBR}_{1}$ (a) and $\mathrm{MBBR}_{2}$ (b) after overnight aeration when purpule dots are not visible on the surface of biofilom in $\mathrm{MBBR}_{1}$ (c) and in $\mathrm{MBBR}_{2}$ (d), after overnight aeration and cutting carrier when purpule dots are visible inside the biofilm in $\mathrm{MBBR}_{1}(\mathrm{e}, \mathrm{f})$, but not visible inside the

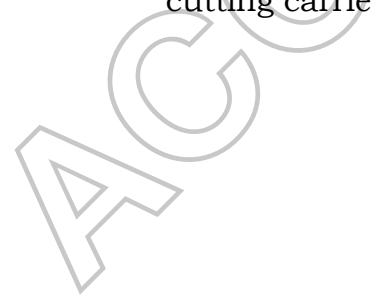
biofilm in $\mathrm{MBBR}_{2}(\mathrm{~g}, \mathrm{~h})$ 


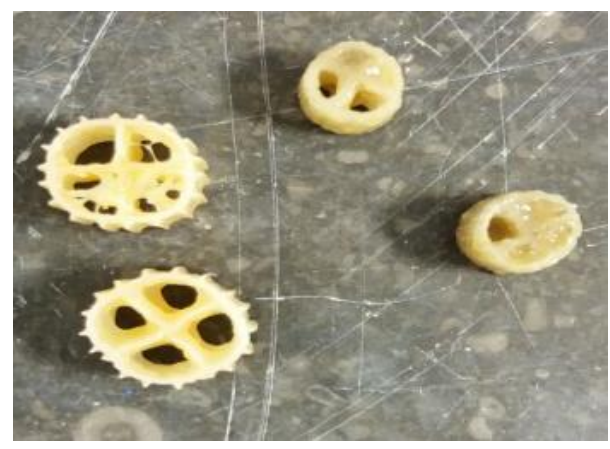

Fig 8: Kaldnes $\mathrm{K}_{1}$ micro carriers still almost full of biomass after PS feeding and Kaldnes $\mathrm{K}_{1}$ carriers which have very thin layer of biofilm after PS feeding

Table 1: Characteristics of Kaldnes $\mathrm{K}_{1}$ bio-carrier

\begin{tabular}{|c|c|c|}
\hline Characteristics & $\begin{array}{c}\text { Kaldnes } \mathrm{K}_{1} \\
{[4]}\end{array}$ & Kaldnes $\mathrm{K}_{1}$ micro [37] \\
\hline Material & High-density polyethylene & High-density polyethylene \\
\hline Shape & cylinder & 6 \\
\hline $\begin{array}{c}\text { Nominal diameter }(\mathrm{mm}) \\
\text { Nominal length } / \text { thickness } \\
(\mathrm{mm})\end{array}$ & 7.2 & 6 \\
\hline Apparent density $\left(\mathrm{kg} / \mathrm{m}^{3}\right)$ & 150 & 413 \\
\hline $\begin{array}{c}\text { Specific surface area } \\
\left(\mathrm{m}^{2} / \mathrm{m}^{3}\right)\end{array}$ & 500 & 900 \\
\hline
\end{tabular}

